\title{
Vloek, skel en vulgariteit: Hantering van sosiolinguisties aanstootlike leksikale items
}

\section{Dekker, Buro van die Woordeboek van die Afrikaanse Taal}

\begin{abstract}
Swearing, Abuse and Vulgarity in Language: The Lexicographical Treatment of Sociolinguistically Offensive Lexical Items. This article limits itself to some thoughts on the lexicographical handling of swearing, abuse and ordinary "bad language". It examines the faults made in the treatment of Afrikaans fok (English fuck), together with some of its compounds, related lemmata, idioms and other ramifications. A very noticeable evasion of linguistic reality is demonstrated and discussed. A draft is presented of more realistic definitions, and the labelling explained. Labels indicating swearing, abuse, insult and the like belong to a series concemed with stylistic functioning and should be distinguished from those indicating sociolinguistic status, like oulgar, colloquial, eleoated, etc., with which they are traditionally grouped on a graded scale.
\end{abstract}

Keywords: SWEARING, ABUSE, VULGARITY, LINGUISTIC REALITY, REALISTIC DEFINITIONS, STYLISTIC LABELLING, SOCIOLINGUISTIC LABELLING, LEXICOGRAPHY

Opsomming: Hierdie artikel wil nie dit wat in onlangse jare oor die leksikografiese bewerking van vloek, skel en ordinêre vulgariteit in die taal geskryf is, saamvat of ontleed nie, ${ }^{l}$ maar probeer slegs om 'n paar praktiese gedagtes oor die onderwerp te ontwikkel. Dit ondersoek die foute wat met die bewerking van die lemma fok en ' $n$ aantal van sy komposita, verwante lemmas, idiome en ander ramifikasies begaan is. ' $n$ Baie opvallende vermyding van die talwerklikheid word blootgelê en bespreek. 'n Ontwerp vir meer realistiese definisies word voorgelê en die etikettering verduidelik. Die etikette oloek, skeltaal, neerhalend en dies meer het betrekking op stilistiese funksies en behoort as ' $n$ aparte reeks onderskei te word van die reeks etikette wat sosiolinguistiese status aandui, scos vulget, geselstaal of verhewe, waarmee dit tradisioneel op 'n gegradeerde skaal saamgegroepeer word.

Sleutelwoorde: VLOEK, SKEL, VULGARITEIT, TAALWERKLIKHEID, REALISTIESE DEFINISIES, STILISTIESE ETIKETTE, SOSIOLINGUISTIESE ETIKETTE, LEKSIKOGRAFIE

1 Du Toit (1989) vat die jongste stand van die internasionale gesprek en die Afrikaanse bydraes saam en voer dit verder. Sy maak daarby o.a. gebruik van Feinauer (1981) se ondersoek na die taalkundige gedrag van vloekwoorde in Afrikaans. 


\section{Die kliniese benadering}

Die dokter wat sou weier om dinge te ondersoek waaroor hy nie aan tafel kan praat nie, sal sy pasiënte spoedig afgee - indien nie aan die graf nie, dan ten minste aan 'n kollega. Die woordeboekmaker wat nie klinies onbetrokke omgaan met woorde en uitdrukkings wat hy nie in sy huis duld nie, stel die geloofwaardigheid van sy woordeboek in gevaar. Hy moet hulle met tegniese kundigheid en effektief hanteer, soos wat 'n munisipaliteit met riolering doen.

"Klinies onbetrokke" wil nie sê dat die leksikograaf geen persoonlike standpunt teenoor sodanige leksikale items moet inneem nie. Dit gee te kenne dat hy in sy werk die betekenis, die toepassings en die taalgebruikers se persepsies van daardie items korrek moet waarneem, ontleed en beskryf en hom daarby nie laat verblind of voorsê nie - nie deur sy eie standpunt nie, en ook nie deur die sosiale druk van die dag nie. Dit geld natuurlik ook vir die metaleksikograaf wat hom besin oor die manier waarop woordeboeke aanstootlikhede in die taal hanteer.

\section{2. 'n Gevallestudie: fiksie in die leksikografie}

Die behandeling wat die Afrikaanse woord fok en sy samestellings en afleidings in die Afrikaanse verklarende leksikografie ondervind, dien as ' $n$ model van hoe ' $n$ aanstootlike leksikale item nie gehanteer moet word nie.

Die Verklarende Afrikaanse Woordeboek se artikel lyk soos volg in die eerste uitgawe van 1936:

fok, ge-, teel (vee), laat aanteel.

In die sesde uitgawe, 1972, word onverklaarde samestellings bygevoeg:

$$
\text { fok }^{2} \text {, (w), ge-, teel van vee, laat aanteel; -ker; -kery. }
$$

Die sewende uitgawe, 2 de druk, 1982, brei die artikel met verdere onverklaarde samestellings uit:

fok $^{2}$, (w), ge-, teel van vee, laat aanteel; -hings; -ker; -kery; -ram.

(My afleiding: Die woord soos beskrywe het 'n normale frekwensie en daar word toenemend nuwe komposita in die taalgebruik opgeteken.)

Deel II van die WAT bied in 1956 aan:

fok $^{2}$, w. (w.g.) Teel (van diere).

fok: ..hings, ..kery, ..ram, ..skaap, ..vee. 
fok'dier. Aanteeldier (met 'n gebruiksvoorbeeld uit die poësie van S.V. Petersen: Trekdier en jukdier / en melkdier en fokdier ...).

fok'ker, fokkers. Teler van vee.

(Afleiding: Die werkwoord is weinig gebruiklik, maar met baie samestellings en afleidings, waaronder minstens fokdier en fokker ' $n$ normale frekwensie het.)

In die eerste uitgawe van die $H A T$ staan die volgende inskrywings:

fok, ww. (gefok). Minder gewoon vir teel.

fok'dier. Dier wat vir teeldoeleindes aangehou word, veral stoetdier.

fok'ker, (-s). Iemand wat diere teel; teler. fok'kery.

In die hersiene uitgawe van 1979 is al drie die lemmas geskrap.

(My afleiding: die woord fok was tot en met 1965 minder gewoon, hoewel fokdier en fokker, soos hier gedefinieer, tog gewone woorde was. Teen 1979 was dit egter so ongewoon dat dit geskrap is.)

In die Nasionale Woordeboek staan daar van die eerste uitgawe (onder die titel Kernwoordeboek van Afrikaans, 1967) tot en met die sesde in 1985:

fok (ge-) ww. (ong.) teel. 'fokkery.

In die sewende uitgawe, van 1987, is die lemma geskrap.

(Afleiding: Fok was maar altyd skaarserig, maar nou kom dit glad nie meer voor nie.)

Ek glo nie daar bestaan enige nodigheid om die geldigheid van bostaande woordeboekinligting te beredeneer nie. Ek beweer sonder meer kategories: 1) die Afrikaanse woord fok kom nie in die Afrikaanse verklarende woordeboeke voor nie (die homoniem wat op seilvaart betrekking het, is nie ter sprake nie); 2) die "woord" fok en sy samestellings en afleidings wat tot onlangs in vier en tans in twee woordeboeke opgeneem is, bestaan nie in Afrikaans nie.

As sommige onder ons sou volhou dat daar waarheid in hierdie stukkie leksikografie steek, sou ons met 'n eenvoudige praktiese toetsie kan vasstel of die woordeboekbeskrywing met die taalwerklikheid ooreenstem. Ons moet dan as die outeurs daarvan in 'n groepie na die vooraanstaande telers, Van der 
Merwe en Van der Merwe, toe gaan, en ons segsman moet die leksikale items uit ons woordeboeke soos volg tot hulle rig, in ooreenstemming met die verklarings wat ons daaraan geheg het: "Menere, dis aangenaam om sulke groot fokkers soos u te ontmoet. Mag ons maar 'n bietjie na u fokkery kyk? Maar sê tog net eers vir ons: Wie van u fok perde en wie is die varkfokker?"

Ons sal dit nie waag nie. Ons erken liewers: wat daar staan, is fiksie. 'n Mens vra jou af hoe dit moontlik is dat ons/ons voorgangers so iets kon lewer.

Ons moet die antwoord in Holland gaan soek. Ons kan ons stukkie Afrikaanse leksikografie met veiligheid aan die Hollandse taalwerklikheid gaan toets deur vir boer Visser daar te gaan vra: "Bent u soms Visser, de hondefokker?", en hy mag dalk rustig antwoord: "Die woont hier naast. Ik fok stieren."

Om redes waarvoor ' $n$ mens heelwat begrip het, is baie Nederlandse leksikale items en/of betekenisse vroeër in ons woordeboeke opgeneem asof hulle Afrikaans is. (Daar is wel vreemd selektief opgeneem. Dit is byvoorbeeld nie vir my duidelik waarom ons nie ook Nederlands fok in die betekenis "bril" en fokken, "bril dra", opgeneem het nie. 'n Fokje is 'n brilletjie, en zij fokt al beteken, volgens Van Dale, "sy bril al".)

Met die instandhouding van die "Nederlandse fiksie" mag daar vandag geen geduld meer wees nie. Dit is slegs die Afrikaanse blokkiesraaiselbedryf wat daarop floreer. (Van die taboewoord fok en sy verwante skram hy na my wete nog weg.) Om ons leksikografie daarvan te suiwer, sal egter 'n taak vir Herkules self wees.

Oor die onbeantwoorde vraag waarom die Afrikaanse woord fok en al sy morfologies-semantiese ramifikasies tot in 1991 nie in 'n enkele verklarende woordeboek gelemmatiseer is nie, kan ek soms net gis. Ek vermoed dat dit by die puristiese WAT van 1956 nie uit onwilligheid was om aanstootlike leksikale items te erken nie maar dat dit toegeskryf kan word aan weerstand teen alles wat reg of verkeerd as Anglisisties aangesien is. (Dit sou in hierdie geval ook ' $n$ sterk bykomende motivering bied vir die teruggryp na die Nederlandse wortels van Afrikaans). 2 Wat ook al die rede was, dit was 'n verkeerde beslissing omdat dit nie van die taalwerklikheid uitgegaan het nie.

Dit ly min twyfel dat hier 'n milde bydrae uit die Engelse leksikon tot die Afrikaanse woordeskat plaasgevind het, met betekenisse, komposita, grammatika en idiome kompleet. Of dit hom aan 'n argaiese Afrikaanse simpleks fok gaan heg het, kan ek nie met sekerheid beantwoord nie, maar die moontlikheid lyk vir my sterk dat Engels fuck en sy derivate ' $n$ volledige ontlening is wat tot fok verafrikaans is. Purisme sou dit stellig as 'n verdringing van die Dietse betekenis van die Dietse leksikale items sien, en derhalwe sou dit die Dietse simpleks, samestellings en betekenisse opneem en die nuwe derivate hulle bestaansreg weier. 


\section{3. 'n Gevallestudie (vervolg): terug na die werklikheid}

Hieronder volg ' $n$ ontwerp vir die definisie van fok, saam met dié van enkele samehangende lemmas, almal ramifikasies van die simpleks. ${ }^{3}$ Dit skets maar ' $n$ vae beeld van die omvangryke scala van sy betekenisnuanses en van die groot produktiwiteit wat dit as morfeem in die vorming van verdere leksikale items aan die dag lê.

Ek het oor feitlik geen databank beskik nie en moes hoofsaaklik empiries werk. Die resultaat is dus in ' $n$ bepaalde sin ook sketsmatige dokumentering van die betreffende woordeskat wat die ore van 'n manspersoon uit 'n gemiddeld beskaafde Afrikaanse milieu bereik wanneer hy hom tussen sy geslagsgenote bevind. Hy hoor aanvanklik, as kind by die huis, hoegenaamd niks daarvan nie. Die grootste deel raak mettertyd aan hom bekend terwyl hy skoolterreine, skrums, maats en universiteitskampusse belewe. Ten slotte word hy gedurende sy militêre lewe aan die volle omvang en sosiolinguistiese geweld daarvan blootgestel. Die gebruiksfrekwensie word dan egter so hoog dat die betrokke items al gou neig om semanties leeg te raak en die vermoë tot emosionele ontlading en teistering te verloor. Dit skep op sy beurt weer 'n behoefte by die gebruiker, wat dikwels tot vindingryke oorspronklike variasies en toepassings lei. Kontak met ander gemeenskappe het die ondergrondse verbreidheid van hierdie substandaard leksikale items vir hierdie skrywer bevestig maar het vir hom min nuwe feite of insigte in dié verband gebring.

fok (vulgêr)

I ww., gefok; byv. en byw. gefok(te).

1 Geslagsomgang (met iem.) hê: Hy fok haar. Die spul katte fok elke nag hier onder my venster.

2 (met byw. frase of setsel) So beweeg dat dit hinderlik is: Waarvoor fok daardie lorries die hele tyd heen en weer hier in ons straat? Moenie daardie sknum so swaai nie, julle fok die hele veld vol! hierso!

II tw. (vloek) Uitroep om iets te beklemtoon: Fok, maar dis koud

UITDR.

IDIOMATIES

fok: fok dit (iets, iemand, ...)! Los dit (los hom, ...); vergeet daarvan (van hom, ...): Nee, fok dit kêrels, ons gaan nooit vanaand klaarkry hierso nie! Fok die gereedskap en bring eers die sementsakke uit die reën uit! Fok hom, hy moet eers betaal voor hy kan saamkom.

Dit is grotendeels ' $n$ toepassing van die riglyne vir etikettering wat die WAT-redaksie neergelê het in sy nuwe redaksionele stelsel. My interpretasie en beredenering van die etikettering is egter my eie en in die gebruik daarvan het ek myself vryhede to.v. die stelsel veroorloof. 
fok: fok jou! Ek hou nie van wat jy sê of doen nie en jy moet dadelik daarmee ophou: Fok jou! Dink jy rêrig ons gaan jou daarmee help?

fok'kery s.nw., fok'spul s.nw.

-fok (vulgêr) Slotkomponent van werkwoordelike komposita waarin -fok die betekenis het van

1 fok (FOK I 1), bv. in rondfok;

2 fok (FOK I 2), bv. in rondfok;

aan'fok, weg'fok;

3 dwing of geweld uitoefen, bv. in rondfok; weg'fok;

4 (iets) met geweld verwoes en verwar, bv, in opfok; deurmekaar'fok, om'fok;

5 aanhou om [met geweld, deur of in iets] te dring of beur totdat die doel bereik is; aan'fok, deur'fok, in'fok.

\section{fok'king (oulgêr) Ook fok'ken.}

I b.nw. Vervlakste: Dis 'n fokking gemors.

- Ook as skeltaal: Die fokking onderwysers wil nie verstaan dat ek nie die huiswerk kan doen nie.

II graadwoord. Baie: Om vandag huis te bou is 'n fokking duur storie. Hier gaan iy fokking hard werk, maatjie.

fok'op s.nw., fokops; fokoppie. (vulgêr) Volslae mislukking en (of) deurmekaarspul: Dis jou laaste kans, jy't nou al twee fokops gemaak. Reg, Kanonnier, jy't net ' $n$ klein fokoppie gemaak en jy gaan net een keertjie om die paradegrond hardloop.

op'fok ww., opgefok; byv. en byw. opgefok(te). (vulgêr)

1 (Iem.) erg slaan of fisiek verrinneweer; sin. opdonder, opmoer: Die skollies het vir Gert behoorlik opgefok.

2 'n Deurmekaarspul of breekspul (van iets) maak; sin. opdonder, opmoer: Moet net nie weer die masjien se bedrading opfok nie! Na die misverstand was hulle verhouding so opgefok dat hulle die vennootskap gelos het.

rond'fok ww., rondgefok; byv. en byw. rondgefok(te). (vulgêr)

1 Met baie mense geslagsomgang hê: Iy sal nooit dink hy is getroud as $j y$ sien hoe hy rondfok nie.

2 Op 'n hinderlike manier rondbeweeg: Die inspekteur fok al die hele middag hier in die fabriek rond. 
3 (Iem. of iets) gedurig erg dwing of manipuleer; sin. ronddonder, rondmoer: Julle slotte moenie nou druk nie, julle fok die hele skrum rond. Sy meisie fok hom vreeslik rond. Daardie arme rondgefokte ouens van sersant Smit se peloton.

\section{Drie etikette vergelyk}

Die aanbieding hierbo het van drie etikette gebruik gemaak: vulgêr, vloek en skeltaal.

(i)

\section{Vulgêr}

Vulgêr is 'n etiket waarmee die sosiolinguistiese status van die leksikale items aangedui word, gemeet aan die standaardtaal. Al die behandelde taalmateriaal, elke lemma en elke aspek daarvan, word daardeur beskryf.

Die kriterium vir hierdie soort etiket is nie of die saak waarna verwys word, onsmaaklik of sensitief is nie, maar of die onvanpaste leksikale item (onvanpas uit die oogpunt van die standaard) uit die leksikon gebruik word. Dit is toelaatbaar om, wanneer nodig geag, in beskaafde, gemengde geselskap of formele situasies oor feitlik enige saak te praat, maar nie om dit met ' $n$ taboewoord te benoem nie. (Die dosent in veeartsenykunde sal in die klas die woord "faeces" gebruik vir wat hy "stront" noem wanneer hy by die hondeteler daarin trap.)

(ii) Vloek

Aan afdeling II van die simpleks en aan die idiome wat daaronder gelemmatiseer is, word vloek as 'n bykomende etiket geheg. Daarmee word te kenne gegee: "Die drie vulgêre tussenwerpsels is vloeke", d.w.s. hulle het die funksie van vloek. Die Romeinse nommering II wys op die onderskeidende grammatikale funksie van die betrokke items. Die etiket vloek wys op 'n ander funksie, een wat parallel loop met en afhanklik is van die grammatikale funksie (tussenwerpsel), maar nie identies daarmee nie - daar bestaan baie tussenwerpsels wat nie vloeke is nie. Ek sou dit as 'n stilistiese funksie bestempel.

(iii)

\section{Skeltaal}

By die b.nw. fokking (FOKKING I), met die statusetiket vulgêr, kry die voorbeeld met fokking onderwyser die ekstra etiket skeltaal by, wat by die voorbeeld met fokking gemors ontbreek. Anders as die stilistiese funksie vloek, loop die stilistiese funksie skeltaal nie volledig parallel met die grammatikale funksie nie: in die een voorbeeld word die b.nw. as skeltaal gebruik en in die ander een nie.

(iv) Die verhouding tussen vloek en skeltaal

Die onderskeidende kenmerke van vloek is beskou as: [+kragwoord] met [temosionele ontlading] en/of [topset om te skok]. Die onderskeidende ken- 
merke van skeltaal is beskou as [+verraai die spreker/skrywer se oordeel oor iemand], [+karaktertekenend] en [+opset om te beledig].

Vloek en skeltaal kan by dieselfde lemma aangetref word:

stront (vulgêr) I s.nw.

1 Menslike en dierlike uitwerpsel: Ek het in ' $n$ bol stront getrap.

2 mv. stronte; $v k w$. strontjie. (skeltaal) Onaangename persoon: $H y$ is ' $n$ regte ou stront.

II tw. (vloek) Uitroep waarmee ontevredenheid of frustrasie te kenne gegee word: Stront! roep hy uit, ek is moeg daarooor!

Vloek en skeltaal neig ook om in dieselfde taaluiting voor te kom. In die geval van stront sal dit beteken dat die woord met die semantiese inhoud van betekenisonderskeiding I 2 en die grammatiese en stilistiese funksie van bet. II gebruik word. Dit kan, met behoud van die res van die artikel, soos volg gehanteer word:

stront (zulgêt)

I s.nw.

1 Menslike en dierlike uitwerpsel: Ek het in ' $n$ bol stront getrap.

$2 \mathrm{mv}$. stront; vkw. strontjie. (skeltaal) Onaangename persoon: $H y$ is ' $n$ regte ou stront.

- Ook as vloek: Stront! Kan jy nie kyk wat jy doen nie?

II tw. (vloek) Uitroep waarmee ontevredenheid of frustrasie te kenne gegee word: Stront! roep hy uit, ek is moeg daarvoor!

Skeltaal is nie soos vloek beperk tot kragwoorde nie:

e'sel s.nw....

1 Dier wat ...

2 (neerhalend) Dom persoon: Hy is ' $n$ regte esel.

- Ook as skeltaal: Esel! Jy plant die blomme onderstebo!

\section{Twee reekse etikette}

Die drie etikette is nie van dieselfde orde nie. Daarom kon vloek en skeltaal addisioneel tot vulgêr aan lemmas of bepaalde betekenisonderskeidings daarvan geheg word.

Hierdie benadering verskil van die gangbare siening. Die taalkunde en die metaleksikografie het baie aandag bestee aan die karakterisering en klassifikasie van sosiolinguistiese items. In Afrikaans is die resultate van die internasionale gesprek en van Feinauer (1981) se navorsing deur Du Toit (1989) saamgevat en deurgevoer tot voorstelle vir leksikografiese bewerking. Erg vereenvoudig, het hierdie waardevolle werk gewoonlik sy praktiese samevatting ge- 
vind in lyste voorgestelde etikette op 'n soort gegradeerde skaal (vgl. Du Toit 1989: 52, wat ook min of meer die basiese reeks vorm wat die WAT in sy sosiolinguistiese etikettering gebruik).

Die indeling, en die klein tradisie, word egter prinsipieel deurbreek deur stilisties-funksionele beskrywings soos vloek en skeltaal (saam met neerhalend, skertsend en verbesonderinge soos rassisties en seksisties) as 'n aparte reeks te onderskei van statusbeskrywings soos vulgêr, sleng, geselstaal en verhewe. Aangesien daar net so goed met andersins "neutrale" woorde "uit die weer uit" of met die naam van die Here gevloek word, en daar geskel word met sosiolinguisties "neutrale" leksikale items soos pampoen of buffel, is dit leksikografies hanteerbaarder en sinvoller om die begrippe vloek en skel heeltemal los te maak van ' $n$ rangorde wat dit noodwendig aan obseniteit en vulgariteit koppel.

\section{Bronne}

Ek het dankbare gebruik gemaak van gestruktureerde groepsgesprekke van die Mederedakteurskomitee van die WAT en van mev. E.L. du Toit se persoonlike deelname daaraan.

Allsopp, R. 1977. The Need for Sociolinguistic Determinants for Status-labelling in a Regional Lexicography. Papers DSNA. Terre Haute, Indiana: Indiana State University.

Du Toit, E.L. 1989. Sosiolinguistiese gegewens in handwaordeboeke van Afrikaans. Ongepubliseerde M.A.-skripsie. Universiteit van Stellenbosch.

Feinauer, A.E. 1981. Die taalkundige gedrag van vloekwoorde in Afrikaans. Ongepubliseerde M.A.skripsie. Universiteit van Stellenbosch.

Gouws, R.H. 1989. Leksikografie. Pretoria: Academica.

Lombard, F.J. 1990. 'n Metaleksikografiese funder ing van Afrikannse skoolwoordeboeke. Ongepubliseerde D.Litt.-proefskrif. Universiteit van Stellenbosch.

\section{Woordeboeke}

De Villiers, M. (Red.). 1967. Kernwoordeboek van Afrikams. 1971, 1977, 1979, 1985, 1987 (2de, 3de, 5de, 6de, 7de uitgawes onder titel) Nasionale Woordeboek. Kaapstad: NASOU.

Kritzinger, M.S.B. (Red.). 1936, 1947, 1956, 1959, 1965, 1972, 1980 (1ste tot 7de uitgawes). Verklarende Afrikanse Woordeboek. Pretoria: Van Schaik.

Schoonees, P.C. (Red.). 1965. F.F. Odendal (Red.). 1979 (2de, hersiene, uitgebreide uitgawe). Verklarende Handwoordeboek oan die Afrikaanse Taal. Johannesburg: Perskor.

Schoonees, P.C. (Red.). 1956. Woordeboek don die Afrikamse Taal. Deel II. Pretoria: Staatsdrukker. 